\title{
Implementation and feasibility of the stroke nursing guideline in the care of patients with stroke: a mixed methods study
}

\author{
Ingibjörg Bjartmarz ${ }^{1}$, Helga Jónsdóttir ${ }^{2,3}$ and Thóra B. Hafsteinsdóttir ${ }^{2,4^{*}}$
}

\begin{abstract}
Background: Nurses often have difficulties with using interdisciplinary stroke guidelines for patients with stroke as they do not focus sufficiently on nursing. Therefore, the Stroke Nursing Guideline (SNG) was developed and implemented. The aim of this study was to determine the implementation and feasibility of the SNG in terms of changes in documentation and use of the guideline in the care of stroke patients on Neurological and Rehabilitation wards, barriers and facilitators, and nurses' and auxiliary nurses' view of the implementation.
\end{abstract}

Methods: A sequential explorative mixed method design was used including pre-test post-test measures and post intervention focus groups interviews. For the quantitative part retrospective electronic record data of nursing care was collected from 78 patients and prospective measures with Barriers and Facilitators Assessment Instrument (BFAl) and Quality Indicator Tool (QIT) from 33 nursing staff including nurses and auxiliary nurses. In the qualitative part focus groups interviews were conducted with nursing staff on usefulness of the SNG and experiences with implementation.

Results: Improved nursing documentation was found for 23 items $(N=37)$, which was significant for nine items focusing mobility $(p=0.002, p=0.024, p=0.012)$, pain $(p=0.012)$, patient teaching $(p=0.001, p=0.000)$ and discharge planning ( $p=0.000, p=0.002, p=0.004)$. Improved guideline use was found for 20 QIT-items $(N=30)$, with significant improvement on six items focusing on mobility ( $p=0.023)$, depression ( $p=0.033, p=0.025, p=0.046, p=0.046$ ), discharge planning $(p=0.012)$. Facilitating characteristics for change were significantly less for two of four BFAlsubscales, namely Innovation ( $p=0.019)$ and Context $(p=0.001)$, whereas no change was found for Professional and Patient subscales. The findings of the focus group interviews showed the SNG to be useful, improving and providing consistency in care. The implementation process was found to be successful as essential components of nursing rehabilitation were defined and integrated into daily care.

Conclusion: Nursing staff found the SNG feasible and implementation successful. The SNG improved nursing care, with increased consistency and more rigorous functional exercises than before. The SNG provides nurses and auxiliary nurses with an important means for evidence based care for patients with stroke. Several challenges of implementing this complex nursing intervention surfaced which mandates ongoing attention.

Keywords: Stroke, Nursing, Evidence based care, Clinical practice guidelines, Feasibility studies

\footnotetext{
* Correspondence: t.hafsteinsdottir@umcutrecht.nl

${ }^{2}$ Faculty of Nursing, University of Iceland, Reykjavík, Iceland

${ }^{4} J u l i u s$ Center for Health Sciences and Primary Care, Nursing Science

Department, University Medical Center Utrecht, Utrecht, The Netherlands

Full list of author information is available at the end of the article
} 


\section{Background}

Stroke generally results in life-altering changes for both patients and their closest family. Patients experience a whole arena of physical and psychosocial impairments [1]. In the long term $25-74 \%$ of patients have to rely on assistance of family for the help in basic Activities of Daily Living (ADL's) like feeding, self-care, and mobility due to the physical impairments, like paralysis of one side of the body, decrease in abilities such as reaching and handling objects [2]. Difficulties with posture and balance make it difficult for patients to walk and mobilize. About one-third of patients are confronted with cognitive impairments such as speaking and comprehending language [3] and many patients have difficulties with memory, which makes it difficult for patients to acquire and maintain new information [4]. Patients are confronted with the huge challenges due to changes in self-identity, role capacity and their abilities to properly function in their personal and social roles as a parent, partner or employee [5]. Stroke rehabilitation is a cyclic process which includes: assessing the needs of the patient, defining realistic and attainable goals, interventions or activities to achieve the goals and reassessment of the progress against the goals [6]. Rehabilitation is provided by an interdisciplinary team of health care professionals, including nurses, physical therapists, occupational therapists and other professionals, who support the patient to regain abilities that were lost. For the patient this is a time-intensive, effortful and often exasperating process [5, 7]. There is strong evidence that taskoriented training aiming to target functional tasks and ADL's can assist the natural recovery pattern of functional recovery [6]. Task-specific and context-specific training are well accepted evidence based principles in stroke rehabilitation as well as the principle that increased intensity of training facilitates recovery $[6,8,9]$. Goals for training need to be relevant for the patient and occur in the patient's environment, preferably his home surroundings. Generally, the literature emphasizes that patients with stroke need more rehabilitation training $[8,9]$.

Neuroscience nurses in stroke care are increasingly adapting to Evidence Based Practice integrating the best available evidence from well-designed studies with clinician's expertise and with information about patient preferences and values in making the best clinical decisions [10]. Although many Interdisciplinary Stroke Practice Guidelines have been developed for the rehabilitation and management of patients with stroke, these guidelines are often not routinely incorporated into daily nursing practice. Among the reason for this is the fact that these guidelines often lack information about early detection of problems using valid and reliable instruments and interventions relevant and feasible for nurses to use in the daily context of stroke care and are not routinely incorporated into the daily patient care $[4,11$, 12]. In an attempt to provide information on various important areas in stroke care, nurses, patients and health care professionals in Iceland and the Netherlands collaborated in developing the Clinical Nursing Rehabilitation Stroke Guideline Stroke (CNRS-Guideline) [13]. Systematic reviews were conducted on interventions and instruments feasible for nurses to use in following areas: mobility and ADL [9], communication and aphasia [3], depression (in patients with/without aphasia) [14, 15], falls [16], neglect [17], self-efficacy [18]. A feasibility study provided evidence for the usability of this guideline for patients and nurses in Dutch stroke settings [19]. Continuing work is taking place and studies are conducted with nurses on identification of symptoms of depression in patients with stroke [20,21] and aphasia $[22,23]$, neglect and how to develop and use technical applications in the rehabilitation of patients with stroke residing at home. Based on this work, the Stroke Nursing Guideline (SNG) was developed and adapted including recommendations targeting among other important elements like mobility and ADL, falls, depression, pain and education of patients and family [24].

Nurses, as key members of the rehabilitation team, provide nursing specific rehabilitation through the continuum of care $[8,9]$. They train patients in activities of daily living, as training needs to be functional, task oriented as well as context specific $[6,8,9]$. As patients with stroke need more training, they play an essential role in creating more opportunities for patients to exercise and practice functional tasks outside and inbetween formal therapy sessions [9]. Accordingly nurses need to maximize their contribution in activation of patients and integration of functional and task oriented training exercises in simple activities, targeting mobility and ADL in the context of daily nursing care in order to increase the intensity and duration of rehabilitation exercise and training.

Painful shoulder is a common, complex and distressing complication after stroke which interferes with patients' recovery. Many patients experience painful shoulder in the early stage of stroke, which continues into the chronic stage, with an incidence ranging from 12 to $58 \%$ [25]. Although various therapeutic treatments have been developed, outcome studies show contrasting findings $[25,26]$.

Depression is a frequent complication after stroke affecting up to one third of patients [27]. Depression after stroke negatively impacts patients' participation in rehabilitation, leads to worse functional outcome $[28,29]$ and higher mortality [30]. Although various guidelines recommend screening for depression in all stroke patients [4], depression after stroke remains unrecognized, undiagnosed and under treated [28]. Nurses routinely 
screen patients for depression which increases the early recognition of depression [31] and they effectively identify depression after stroke using the Patient Health Questionnaire [20, 21, 32].

Falls are common among stroke patients with prevalence ranging from 10 to $73 \%[16,33,34]$. The various risk factors for falls reported include: instability when walking, weakness of the lower leg muscles, urinary incontinence, frequent need to go to the toilet, confusion, depression and medication [16], a Barthel Index score below 15, time since stroke longer than 12 weeks, first fall associated with visuospatial neglect [35] older age, increased length of stay [36], greater stroke severity, history of anxiety, history of fear of falling [37], lower functional status and lower cognitive status [38]. Although moderate evidence was found for the ability of instruments to predict risk of fall in patients after stroke, the literature recommends preventive screening for risk of falls and to provide preventive measures for risk of falls in all phases after stroke [16, 33-38].

Education is an important aspect in the care of patients and families during the stroke recovery [39]. Due to the complexity of the impairments and the huge changes in life after the stroke incident, patients and caregivers have diverse educational needs which often are not met [40]. Patients and caregivers reported that they need education about the clinical aspects of stroke, stroke prevention, treatment and functional recovery and caregivers also need information concerning moving and lifting patients, exercises, psychological changes and nutritional issues after stroke, that is tailored to their situation [40]. Lack of knowledge about stroke can lead to misconceptions, anxiety, fear, poor health status and emotional problems $[39,40]$. Therefore patients and caregivers need more and thorough education, tailored to their needs, after the stroke.

The Medical Research Council emphasizes the importance of evaluating feasibility and implementation of complex interventions like guidelines, in terms of acceptance by health care professionals, the nursing staff knowledge and skills and the facilities needed for implementation [41, 42]. Feasibility is referred to as the quality of being useful and practical and involves study of the applicability or practicality, which can be assessed by considering the acceptability of the guideline to clients and staff administering it, the costs and the ease of integrating it into clinical settings [43]. Implementation is defined as the introduction of an innovation in daily routines, demanding effective communication, and removing obstacles [12]. Unfortunately, the literature shows that implementation of CPGs is often not achieved and not following the evidence-based CPGs leads to suboptimal care for many patients [12]. Despite the evidence found for the usability of the earlier CNRS guideline, the fact that it was extensive and included many recommendations was found difficult for implementation [19].

Based on this background the aim of this study was to investigate the implementation and feasibility of the use of a Stroke Nursing Guideline (SNG) focusing on mobility ADL, depression, pain, falls, education and discharge planning, used by nurses and auxiliary nurses in the daily care of patients with stroke and stating the following research questions: a) What is the difference in nursing staff documentation of the screening and application of interventions for activities of daily living, mobility, depression, pain, falls, patient education and discharge planning of patients who receive rehabilitation nursing care before and after implementing the SNG? b) What are the nurses' and auxiliary nurses' view on the acceptability of using the SNG in supporting the provision of daily nursing care? c) What are the nurses' and auxiliary nurses' views on barriers and facilitators to implementing and embedding the SNG within routine daily nursing care?

\section{Methods}

This study used a sequential explorative mixed method design [44], including pre-test post-test measures [45] and focus group interviews [44]. The pre-test post-test was chosen to measure the difference in nursing staff documentation of the screening and application of interventions, whereas the focus group interviews explored the nurses' and auxiliary nurses' views of implementing and using the SNG. The study was conducted in three phases: In phase one (February 2012 to February 2013) pre-test retrospective patient record data were collected from: a) patients' electronic nursing documentation system (ENDS-system) on screening and application of key interventions in stroke care which included items focusing on: activities of daily living, falls, pain, depression, patient education and discharge planning, and b) registered nurses and auxiliary nurses answers on the Barriers and Facilitators Assessment Instrument (BFAI) [46] and the Quality Indicators Tool (QIT) reflecting the SNG. In phase two (April 2013 to the end of December 2013) the SNG was implemented using evidence based strategies including education and training, opinion leaders, posters and reminders $[47,48]$. In phase three (February 2014 to February 2015), the posttest measurements were conducted with nurses and auxiliary nurses and patients assigned to the intervention group (February 2014 to February 2015). The focus group interviews were conducted with a subgroup of nurses and auxiliary nurses in October and November 2014 (Fig. 1). Hereafter, nurses and auxiliary nurses are generally referred to as nursing staff. To provide thorough reporting of the study both STROBE and COREQ statements were used (Additional file 1). 


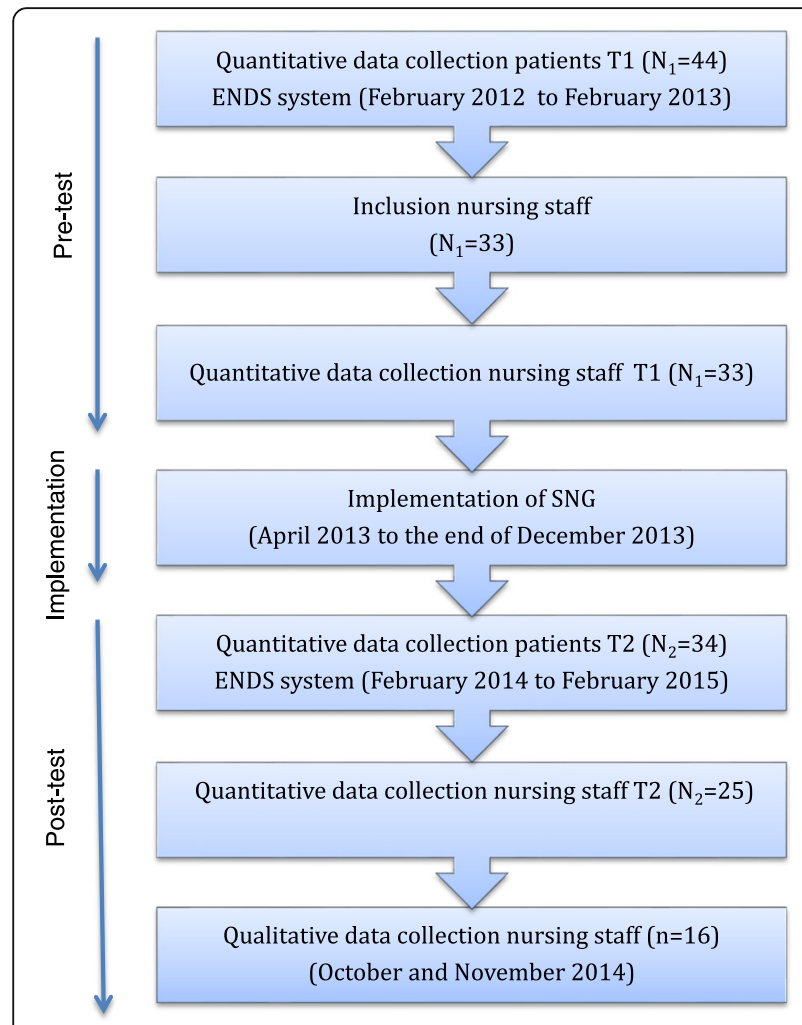

Fig. 1 Flowchart of study design

\section{Setting and participants}

The study was conducted at neurology and rehabilitation wards of a university hospital in Iceland. Patient records were extracted from all patients diagnosed with stroke, older than 18 years of age, admitted to the acute neurological ward and subsequently transferred to the rehabilitation ward for 12 months prior to implementation and for 12 months after implementation. Excluded were patients who died while admitted to the wards. Data were retrieved from 78 patients (34 in the pretest and 44 in the posttest).

All nursing staff, which included registered nurses and auxiliary nurses working on the participating wards $(N=$ 40 , nurses $=22$ and auxiliary nurses $=18$ ), were invited to take part in the study and signed informed consent. Thirty-three nursing staff responded to the pre-test questionnaires, whereas 25 responded to the post-test questionnaires (18 nurses/15 nursing auxiliaries/pretest and 13 nurses/12 nursing auxiliaries/posttest). Sixteen nurses and auxiliary nurses ( $N=8$ each group, respectively) took part in three focus group interviews.

\section{The stroke nursing guideline}

The Stroke Nursing Guideline (SNG) aims to provide an overview of evidence based recommendations for the daily nursing care and rehabilitation of patients with stroke. The SNG was developed based on systematic reviews and studies focusing on following areas: mobility and ADL [8, 9], falls [16, 33-38, 49, 50], pain [25], depressive symptoms $[14,15,20,21,28-32]$, education $[39,40,51]$, as well as the CNRS-Guideline [13]. The authors, who all have extensive experience in stroke care and research, made the first selection of important interventions based on the literature, which were formulated as recommendations for the SNG.

Among important aspect of implementation and acceptability of new guidelines like the SNG is the fact that all professionals involved in the care of patients with stroke agree and support the guideline. Therefore, we approached a group of 20 interdisciplinary professional experts, to critically review the content, readability, layout and usability of the guideline. These experts included: nine nurses and of these seven worked on the wards, all with BSc degree in nursing and long experience in neuroscience nursing, of these four had a MSc degree and two had a $\mathrm{PhD}$ degree; six physical therapists, two occupational therapists; one psychologist; one rehabilitation physician and one neurologist. These professionals all agreed on the content of the guideline recommendations and their comments mainly focused on the readability, layout and usability of the SNG. There were no specific differences between the professionals in their views about the SNG and based on the expert feedback, the guideline was adapted and optimized.

The final SNG included a total of 23 recommendations focusing on assessment and therapeutic interventions categorized in the following areas: 1) activities of daily living and mobility and falls (14 recommendations), 2) pain/shoulder pain (3 recommendations); 3) depression (3 recommendations); 4) patient education (2 recommendations) and 5) discharge planning (1 recommendation). The guideline also included thorough instructions with photos on how to use the recommendations, with chapters on: background information, definition of concepts, flow-scheme of how to use the guideline, recommendations for the assessment of various outcomes including: mobility and activities of daily living using, the Functional Independence Measure (FIM) [52]; risk of falls using the Morse Fall Scale (MFS) [49]; shoulder pain using a visual analogue scale; depressive symptoms with Patient Health Questionnaire-9 (PHQ-9) [53, 54] and recommendations focusing on therapeutic interventions for the aforementioned areas as well as appendices with the instruments and instructions with photos on how to assist patients with mobility, exercises and positioning. The SNG guideline was made ready to use in a digital, online form as well as a 32 page manual including a plasticized card (pocket size) which was available for all staff. 


\section{Data collection}

Patient data were retrieved from the ENDS-system including: demographic and health care data: age, sex, living situation, height, weight, health history, the clinical diagnosis of stroke and the type of stroke (provided by a neurologist, based on a CT-scan or an MRI). Also, the following data concerning 37 items on screening and application of key interventions in stroke care were retrieved from the ENDS-system:

a) activities of daily living and mobility (8 items) screened with the Functional Independence Measure (FIM) [52] within $72 \mathrm{~h}$ of admission, including diagnosis of mobility and ADL, evaluation of care, limitation in self-care, mobilization facilitation within $24 \mathrm{~h}$, frequency of training exercises, walking exercises, training of ADL activities.

b) fall and fall risk (1 item) screened within $72 \mathrm{~h}$ using the Morse Fall Scale (MFS) [49], consisting of six items reflecting risk factors of falling: (i) history of falling, (ii) secondary diagnosis, (iii) ambulatory aids, (iv) intravenous therapy, (v) type of gait and (vi) mental status. Total score ranges between 0 and 125 [49]. MFS had been translated into Icelandic (MFS-I) and piloted with the nurses to determine their understanding of wording of items. Interrater reliability was examined and the level of agreement was $84 \%(K=0.68)$ [49].

C) pain assessment and pain treatment with special focus on shoulder pain (14 items): Patients were asked about pain/shoulder pain and pain assessment was conducted using a visual analogue scale and the following interventions were provided: pain treatment (warm cold packages, massage), pain medication given, non-pharmacological treatment given, comforting, massage, relaxation, distraction, pain treatment never given, evaluation of pharmacological pain treatment).

d) patient screening for depressive symptoms (4 items): Patients were asked about psychological distress, nursing diagnosis of depression, consultation of other professionals for the diagnosis and treatment. Depression was screened with the Patient Health Questionnaire-9 (PHQ-9). The scores are summed to produce a value ranging from 0 (no depression) to 27 (all symptoms occurring nearly every day $[53,54]$. Symptoms of depression with the PHQ-9 was only screened in the posttest because no depression scale existed in the electronic documentation system prior to the implementation.

e) patient (and family) received education (4 items) including standard information about stroke and rehabilitation, education brochure received, education repeated and tailored to the patient's (and family) needs. f) discharge planning (6 items) which included: basic discharge planning using electronic patient record, quality discharge planning, patient discharge interview, social support recommended/planned, aftercare recommended/planned, written recommendations.

Demographic data of the nurses and auxiliary nurses were collected including: age, gender, education, experience/length of time working in stroke rehabilitation $(0$ 2 years, $3-10$ years, $>10$ years), current function (full time equivalent), courses on nursing stroke rehabilitation.

Barriers and facilitators for implementation were measured with the Barriers and Facilitators Assessment Instrument (BFAI) [46], with 27 questions, addressing four domains: characteristics of the innovation i.e. the guideline; characteristics of the care provider, patient characteristics and context (organizational, social, political factors). The questions are positively as well as negatively formulated on a five-point Likert scale, ranging from 5 (strongly agree) to 1 (strongly disagree). The BFAI is a standardized and reliable instrument, with an item response of $>90 \%$, with each item having a distinctive character and was found to be useful for evaluating barriers and facilitators and with Cronbach's alpha for the four domains ranging from 0.63 to 0.68 [46].

The use of the guideline was measured with a Qualitative Indicator Tool (QIT), developed by the authors, based on the SNG recommendations as and included 30 statements, for the nurses. The QIT statements focused on the main areas of the SNG: a) mobility and activities of daily living (7), b) falls (1), c) depression (9), d) pain/ shoulder pain (5), e) patient education (5) and f) discharge planning (3) and inquired if the nurses provided care according to the SNG-recommendations and were phrased in line with the following statement as an example: "I conduct assessment of mobility and self-care activities on admission with a) the FIM-scale, b) the scale in the electronic patient health records, c) both FIM scale and the scale in the electronic patient health records", which were scored on a five point Likert scale (almost never or $<10 \%$ to very often or $>90 \%$ ). The face validity of the QIT was evaluated by a group of five experts and included clinical nurse specialists and nurse researchers with extensive experience in stroke nursing and rehabilitation, who reviewed the statements and concluded that the 30 statements were relevant for the daily care and rehabilitation of patients with stroke. Further psychometric testing of the QIT needs to be conducted.

\section{Focus group interviews}

Three Focus Group Interviews were conducted with eight nurses and eight auxiliary nurses after the implementation [44]. The interviews were chaired and conducted by a 
clinical nurse specialist in geriatric nursing, who is a seasoned researcher and has experience with focus group discussion, but was not involved in this study in other ways. An assistant observed and took notes on the interviews, how participants responded to questions and how the discussion evolved. The project manager (IB) invited participants to the interviews but did not take part in them. In the first interview seven nurses $(N=2)$ and nurse auxiliaries $(N=5)$ took part, in the second interview four nurses $(N=4)$ and no auxiliary nurses took part, whereas in the third interview five nurses $(\mathrm{N}=2)$ and nurse auxiliaries $(N=3)$ took part. An interview guide was used to guide the interviews. The findings of the previous interviews were used to guide discussion in the subsequent interviews (Additional file 2).

\section{Procedure}

\section{Phase 1. Pre-test}

Quantitative data of the pre-test group of patients were collected from the Ends-system prior to the implementation of the SNG. Pre-test measures of the nurses and auxiliary nurses were collected as well, after presenting the study including the purpose and procedures in a meeting with the nurses, nurse auxiliaries and managers of the ward.

\section{Phase 2. Implementation}

The SNG was implemented in the course of nine months using the following implementation strategies which were based on the literature [47, 48]: a) Stroke Nursing Guideline: all the registered nurses and auxiliary nurses received both a printed and plasticised version as well as a digital version. b) Education and Training sessions: All the registered nurses and auxiliary nurses as well as other professionals were invited to take part in one of two, four hour education and training session in how to use the recommendations, the screenings instruments and interventions recommended. This training was strongly recommended for the nurses and the nurse auxiliaries. c) Opinion leaders: seven nurses (5 registered nurses and 2 auxiliary nurses) took on the role of an opinion leader. The opinion leaders were experts in the content and application of the guideline. They followed up on the implementation of the guideline, observed if recommendations were used and gave advice to other colleagues concerning the application of the recommendations. d) Posters and reminders: Posters and reminders were placed on the walls of the wards to remind the nurses on using the guideline and e) E-mails: Regular emails were sent to all the registered nurses and auxiliary nurses explaining the intervention protocol and the recommendations.

\section{Phase 3. Post-test}

After the implementation period, the post-test data collection took place. The same data were collected as in the pre-test. In addition, focus group interviews were conducted with a subgroup of nurses and auxiliary nurses. The focus group interviews took place in a quiet room within the nursing science department and not within the hospital wards.

\section{Data analysis}

Quantitative data were analyzed using descriptive statistics to describe the characteristics of the patients including means (SD), medians (IQR) or $\mathrm{n}(\%)$. Frequencies and percentages were reported for the recommendations used, perceived barrier quality indicators were analyzed and reported for both control and comparison group. Associations were calculated for specific patients' health problems and specific recommendations using Fisher's exact Test (2-sided) and Spearman's rho. All data were assessed for normality, which was taken into account when choosing the appropriated statistical method used. For analyzing the Perceived barriers and facilitators measured with the BFAI, the items 4-15 and 17-27 were revised so that a higher score reflected positive and low score negative view of participants. A $p$-value of $<0.05$ was considered significant. The SPSS version 20 (SPSS inc., Chicago IL, USA) was used.

Qualitative data analysis was carried out with content analysis (44). The first stage in the qualitative analysis process involved transcription of the interviews. The transcripts were studied repeatedly by two researchers $(\mathrm{IB} / \mathrm{HJ})$. Following the transcription, the content was checked for accuracy, after which the data were analyzed. The first level of analysis involved grouping that under broad headings in the interview guide and data were categorized to answer the research question(s) by extracting the quotes from the transcribed interviews. The authors read and reread the transcribed interviews, initial themes were identified using open coding of the data. Differences in themes were resolved by discussions (IB/HJ/TBH). Member checking was employed to ensure content validity by obtaining agreement from participating nurses on a summary of the focus group findings.

Quantitative and qualitative results were integrated after data analysis [44], results of these data were presented separately but integrated in the discussion section.

\section{Research ethics}

The study was conducted in accordance with the Declaration of Helsinki (revised form, Seoul 2013) [55]. The Hospital Ethics Committee (1909201223-2012, 04112013232012, 1,701,201,423-2012,1,603,201,523-2012， 1,007,201 ,523-2012, 23/2012), the Ethics Committee of the CEO of Medicine (3,005,201,516, 16LSH-14,1,203,201,516), Human 
Resource Council of the hospital (2505201216) and the Data protection Authorities (2,012,050,710, 2,014,010,073, S67172014) approved the study. All the nurses and nursing auxiliaries consented to participation and the use of direct quotes in this paper by signing an informed consent form.

\section{Results}

\section{Patients and nurses characteristics}

In total data were extracted from 78 patients. Analysis was based on data from 44 patients in the pre-test group (T1) and 34 patients in the post-test group (T2) and Patients in both groups were comparable on main demographic variables, except that the patients in the post-test group were younger $(p=0.051)$ (Table 1$)$. A total of 33 nursing staff were included in the study and of these 18 were registered nurses (54\%) and 15 were nursing auxiliaries (46\%). Of the group 25 (76\%) worked on the rehabilitation ward whereas eight (24\%)

Table 1 Characteristics of patients

\begin{tabular}{|c|c|c|c|}
\hline & $\begin{array}{l}\text { Pre-test } \\
(N=44)\end{array}$ & $\begin{array}{l}\text { Post-test } \\
(N=34)\end{array}$ & $p$-value \\
\hline & Group & Group & \\
\hline Gender $(n, \%)$ & & & 0.246 \\
\hline Men & $29(66)$ & $18(53)$ & \\
\hline Women & $15(34)$ & $16(47)$ & \\
\hline Age $(M, S D)$ & $\begin{array}{l}65.5 \\
(13.12)\end{array}$ & $\begin{array}{l}58.2 \\
(17.90)\end{array}$ & 0.051 \\
\hline \multicolumn{4}{|l|}{ Disease diagnosis $(n, \%)$} \\
\hline Hemorrhage & $11(25)$ & $8(24)$ & 0.881 \\
\hline Infarct & $33(75)$ & $26(76)$ & \\
\hline Living situation $(n, \%)$ & & & 0.763 \\
\hline Single/lives alone & $11(25)$ & $10(30)$ & \\
\hline Married/cohabiting & $32(75)$ & $23(70)$ & \\
\hline $\begin{array}{l}\text { Employment status prior to } \\
\text { admission }^{\mathrm{a}}(\mathrm{n}, \%)\end{array}$ & & & 0.438 \\
\hline Full employment & $12(29)$ & $10(35)$ & \\
\hline Part time & $2(5)$ & $1(3)$ & \\
\hline Not working & $2(5)$ & $1(3)$ & \\
\hline Retired & $20(49)$ & $9(31)$ & \\
\hline Disability benefits & $5(12)$ & $8(28)$ & \\
\hline \multicolumn{4}{|l|}{ Nationality $(n, \%)$} \\
\hline Icelandic & $44(100)$ & $31(91)$ & 0.044 \\
\hline Non-Icelandic & $0(0)$ & $3(9)$ & \\
\hline \multicolumn{4}{|l|}{$\begin{array}{l}\text { Length of hospital stay days } \\
(\mathrm{M}, \mathrm{SD})\end{array}$} \\
\hline Neurological ward & $\begin{array}{l}17.8 \\
(13.10)^{b}\end{array}$ & $\begin{array}{l}14.7 \\
(7.162)\end{array}$ & 0.225 \\
\hline Rehabilitation ward & $\begin{array}{l}58.0 \\
(48.27)\end{array}$ & $\begin{array}{l}58.8 \\
(56.71)\end{array}$ & 0.135 \\
\hline
\end{tabular}

${ }^{\mathrm{a}}$ Missing data, ${ }^{\mathrm{b}} 2$ patients excluded due to unusual long acute phase worked on the neurological ward. Most of the staff worked part-time (Table 2).

\section{Difference in documentation of SNG key interventions before and after implementation}

Documentation of the 37 items on screening and application of key interventions in stroke care, was improved in 23 items after implementation. Significant improvement was found on the six following items: a) three items in ADL and mobility: Assess with FIM $<72 \mathrm{~h}$ of admission $(p=0.002)$, Mobilization facilitation within $24 \mathrm{~h}(p=0.024)$, Training of ADL $(p=0.022)$ and b) three items on patient education: Patient education $(p=$ $0.001)$, Educational brochure provided $(p=0.000)$ and Education repeated $(p=0.049)$. No change was found in the documentation of five items (4 pain variables, 1 depression). Significant worse documentation was found for the item Patients asked about pain $(p=0.012)$, whereas the worse documentation on the remaining eight items was non-significant (3 ADL, 4 pain, 1 depression) (Table 3).

\section{Difference in the use of the SNG measured with the quality indicator tool}

The nurses' use of the guideline measured with the 30 item QIT, showed enhanced use on 20 indicators, six of which the improvement was significant (Table 4). Improvement in use of the guideline was shown in seven indicators (of eight) on Mobility and $A D L$, with significant improvement in one item, namely Assist and supervise patient with exercises according to physical therapists recommendations $(p=0.023)$. Improvement was shown in four (of eight) indicators on Depression, with significant improvement for three items: Assess symptoms of depression with a depression scale ( $p=$ 0.033), Take time to talk with patient $(p=0.046)$, Take time to talk with family $(p=0.046)$. Non-significant improvement trend was shown in four (of five) indicators on pain as well as on two (of five) indicators on Patient education indicators. Improvement was shown on two (of four) indicators on Discharge planning and of these significant improvement was found for the indicator Document discharge planning in patient electronic health records. On the remaining 10 indicators no improvement was found (Table 4).

In the analysis of the focus group interviews the following six themes emerged: Improved quality of care, Content known to staff, Convenient and concise, More use of instruments, More consistency, Illustrative and instructive. The focus group interviews showed that the nurses and auxiliary nurses viewed the use of the guideline to improve nursing care. They knew the content of the guideline, used it and found the guideline practical and easy to use. The use of the SNG made them focus more 
Table 2 Characteristics of nurses and auxiliary nurses $(N=33)^{a}$

\begin{tabular}{|c|c|}
\hline & $N(\%)$ \\
\hline \multicolumn{2}{|l|}{ Ward $(n, \%)$} \\
\hline Rehabilitation & $25(76)$ \\
\hline Neurological & $8(24)$ \\
\hline \multicolumn{2}{|l|}{ Profession (n, \%) } \\
\hline Registered nurses & $18(54)$ \\
\hline Auxiliary nurses & $15(46)$ \\
\hline \multicolumn{2}{|l|}{ Age (years) (n, \%) } \\
\hline$<34$ & $10(30)$ \\
\hline $35-44$ & $3(10)$ \\
\hline $45-54$ & $5(15)$ \\
\hline $55-64$ & $10(30)$ \\
\hline$>65$ & $5(15)$ \\
\hline \multicolumn{2}{|l|}{ Highest educational degree/diploma (n, \%) } \\
\hline Nursing Bachelor of Science/Diploma & $14(43)$ \\
\hline Postgraduate nursing program & $5(15)$ \\
\hline Nursing auxiliary program & $12(36)$ \\
\hline Postgraduate nursing auxiliary program & $2(6)$ \\
\hline \multicolumn{2}{|l|}{ Full time equivalent work (FTE) (n, \%) } \\
\hline $100 \%$ & $5(16)$ \\
\hline $50-90 \%$ & $24(77)$ \\
\hline $40-49 \%$ & $2(7)$ \\
\hline \multicolumn{2}{|l|}{ Working experience in nursing (years) (n, \%) } \\
\hline$<4$ years & $1(3)$ \\
\hline $1-5$ & $7(21)$ \\
\hline$\geq 6$ & $25(76)$ \\
\hline \multicolumn{2}{|c|}{ Working experience in stroke rehabilitation (years) $(n, \%)$} \\
\hline $0-2$ & $6(19)$ \\
\hline $3-10$ & $13(42)$ \\
\hline$>10$ & $12(3)$ \\
\hline \multicolumn{2}{|c|}{ Nursing stroke rehabilitation courses attended $(n, \%)$} \\
\hline Mobility/self-care & $19(58)$ \\
\hline Psychological care & $13(39)$ \\
\hline Patient education & $12(36)$ \\
\hline Falls & $12(36)$ \\
\hline Pain & $15(45)$ \\
\hline Other & $2(6)$ \\
\hline
\end{tabular}

${ }^{\mathrm{a}}$ There is lack of responses on all items, varying between 2 and 4

on specific issues like depression and falls and provided accurate and systematic way to evaluate and communicate about patients' progress. It provided consistency in care as they provided care and exercises in the same way, with consistency in intensity, frequency, with more rigorousness and better use of ergonomics than before. They found the guideline layout, including photos and diagrams, to be illustrative and instructive for patients, who are mobilized and cared for in a convenient and consistent way. Family members were more trustful in that the patients received optimal care. At the end of the focus group interview, the nurses and auxiliary nurses participating were individually asked to rate their view of the general usefulness of the SNG on visual analogue scale (ranging from 1 indicating not useful to 10 indicating very useful) which was valued with a mean score of 7.7 (range 5.59.0)(Table 5).

\section{Nursing staff view of the implementation process}

Facilitating characteristics for change were significantly less for two of the four subscales, namely Innovation $(p=0.019)$ and Context $(p=0.001)$ on the BFAI, whereas no change was found for Professional and Patient subscales (Table 6). Contrary to these results, the nurses and auxiliary nurses reported positive experiences, when asked to rate the success of implementation on visual analogue scale (ranging from 1 indicating not successful to 10 indicating very successful) which was valued as successful with a mean score of 7.5 (range 6.0-8.5). They maintained that the implementation brought a totally different view on mobilization in daily care (Table 5). In the analysis of the focus group data, the following six themes emerged: Nursing rehabilitation defined and integrated, Physical exercise Individualized, Enhanced patient and family teaching, Coherent and consistent leadership, Improved staff education and Less visible nursing care received attention. The focus group interviews showed that the nurses and auxiliary nurses found that throughout the implementation consistent and coherent leadership was provided. They found that essential components of rehabilitation had been defined and integrated into daily nursing care (standing up and sitting down, going to the toilet). The exercise guidelines made individual instructions from other professionals less needed. There was enhanced patient and family teaching, good teaching material, and consistent and good staff education. Previous less visible aspects of nursing care, after implementation, received attention and recognition among all staff. Of particular significance was the contribution this makes to the entire rehabilitation of patients with stroke (Table 5).

\section{Discussion}

This study investigated the implementation and feasibility of a newly developed Stroke Nursing Guideline using electronic data on patient outcomes before and after implementation and data from nursing staff on barriers and facilitators for implementation, quality indicators before and after implementation of the SNG and the views and opinions of nursing staff towards the guideline. In this way we aimed to gain better understanding of the implementation, use and feasibility of the SNG in daily 
Table 3 Comparison of documentation of Quality Indicator Tool items of the Stroke Nursing Guideline

\begin{tabular}{|c|c|c|c|c|c|}
\hline & \multicolumn{2}{|c|}{ Pre-test Group $(\mathrm{N}=44)$} & \multicolumn{2}{|c|}{ Post-test Group $(N=34)$} & \multirow[t]{2}{*}{$p$-value } \\
\hline & No $(\%)^{b}$ & Yes (\%) & No $(\%)$ & Yes (\%) & \\
\hline \multicolumn{6}{|l|}{ Mobility and Activities of daily living ( $n, \%)$} \\
\hline Assess. with FIM $<72 \mathrm{~h}$ of admission & $33(75)$ & $11(25)$ & $14(41)$ & $20(59)$ & 0.002 \\
\hline Nursing diagnosis of mobility & $4(9)$ & $39(91)$ & $1(3)$ & $33(97)$ & 0.261 \\
\hline Evaluation of care & $33(75)$ & $11(25)$ & $28(85)$ & $5(15)$ & 0.292 \\
\hline Limitation in self-care & $17(39)$ & $27(61)$ & $9(26)$ & $25(74)$ & 0.258 \\
\hline Mobilization facilitation $<24 \mathrm{~h}$ & $19(47)$ & $21(53)$ & $7(22)$ & $25(78)$ & 0.024 \\
\hline Frequency of training exercises & $12(35)$ & $22(65)$ & $10(39)$ & $16(61)$ & 0.180 \\
\hline Walking exercises & $4(14)$ & $25(86)$ & $4(17)$ & 20(83) & 0.778 \\
\hline Training of ADL activities & $12(30)$ & $28(70)$ & $2(7)$ & $26(93)$ & 0.022 \\
\hline \multicolumn{6}{|l|}{ Falls $(n, \%)$} \\
\hline MORSE screening & $34(77)$ & $10(23)$ & $21(62)$ & $13(38)$ & 0.306 \\
\hline \multicolumn{6}{|l|}{ Pain and pain treatment $(n, \%)$} \\
\hline Patients asked about pain & $10(23)$ & $34(77)$ & $17(50)$ & $17(50)$ & 0.012 \\
\hline Pain diagnosis & $10(23)$ & $34(77)$ & $6(18)$ & $28(82)$ & 0.582 \\
\hline Pain assessment with a scale & $23(74)$ & $8(26)$ & $16(73)$ & $6(27)$ & 0.905 \\
\hline Fixed pain treatment & $7(21)$ & $26(79)$ & $9(39)$ & $14(61)$ & 0.144 \\
\hline PN pain treatment & $10(30)$ & $23(70)$ & $8(32)$ & $17(68)$ & 0.890 \\
\hline Non-pharmacological pain treatment & $22(73)$ & $8(27)$ & $12(55)$ & $10(45)$ & 0.159 \\
\hline Comforting & $42(96)$ & $2(4)$ & $32(94)$ & $2(6)$ & 0.589 \\
\hline Massage & $43(98)$ & $1(2)$ & $31(91)$ & $3(9)$ & 0.217 \\
\hline Electrotherapy & $44(100)$ & $0(0)$ & $34(100)$ & $0(0)$ & - \\
\hline Ankle splint & $43(98)$ & $1(2)$ & $34(100)$ & $0(0)$ & 0.564 \\
\hline Relaxation & $44(100)$ & $0(0)$ & $34(100)$ & $0(0)$ & - \\
\hline Distraction & $44(100)$ & $0(0)$ & $34(100)$ & $0(0)$ & - \\
\hline Pain treatment never given & $28(78)$ & $8(22)$ & $21(78)$ & $6(22)$ & 1.000 \\
\hline Evaluation of pain treatment & $4(14)$ & $25(86)$ & $7(33)$ & $14(67)$ & 0.097 \\
\hline \multicolumn{6}{|l|}{ Depressive symptoms ( $\mathrm{n}, \%)$} \\
\hline Psychological distress diagnosis & $18(41)$ & $26(59)$ & $15(45)$ & $18(55)$ & 0.690 \\
\hline Assessment with PHQ9 & - & - & $29(88)$ & $4(12)$ & - \\
\hline Identification of depressive symptoms & - & $3(7)$ & - & $3(9)$ & - \\
\hline $\begin{array}{l}\text { Consultation other professionals for } \\
\text { the diagnosis and treatment }\end{array}$ & $25(58)$ & $18(42)$ & $13(38)$ & $21(62)$ & 0.083 \\
\hline \multicolumn{6}{|l|}{ Patient teaching $(n, \%)$} \\
\hline Patient education & $37(84)$ & $7(16)$ & $15(47)$ & $17(53)$ & 0.001 \\
\hline Educational brochure & $40(95)$ & $2(5)$ & $15(48)$ & $16(52)$ & 0.000 \\
\hline Education repeated & $30(91)$ & $3(9)$ & $30(91)$ & $14(19)$ & 0.049 \\
\hline Participation in teaching sessions & $39(89)$ & $5(11)$ & $27(82)$ & $6(18)$ & 0.397 \\
\hline \multicolumn{6}{|l|}{ Discharge planning ( $n, \%)$} \\
\hline Electronic Patient Record & $11(32)$ & $23(68)$ & $18(42)$ & $25(58)$ & 0.393 \\
\hline Quality Discharge Planning* & $7(30)$ & $16(70)$ & $22(85)$ & $4(15)$ & 0.001 \\
\hline Discharge Interview & $22(69)$ & $10(31)$ & $43(100)$ & $0(0)$ & 0.000 \\
\hline Social support & $7(22)$ & $25(78)$ & $14(38)$ & $23(62)$ & 0.151 \\
\hline Advice follow-up & $20(63)$ & $12(37)$ & $36(92)$ & $3(8)$ & 0.002 \\
\hline Written infomation \& recommendation & $25(81)$ & $6(19)$ & $42(100)$ & $0(0)$ & 0.004 \\
\hline
\end{tabular}

a) $p$-value calculated with Chi square test; $p$-value cursive indicates significant difference between groups;

b) No = very limited information documented; Yes = somewhat good and very good, with relevant information 
Table 4 Difference in nurses' application of 30 quality indicators before and after implementation of the Stroke Nursing Guideline $(N=14)$

\begin{tabular}{|c|c|c|c|}
\hline & Pre-test group M (SD) & Post-test group M (SD) & $p$-value \\
\hline \multicolumn{4}{|l|}{ Mobility and activities of daily living } \\
\hline \multicolumn{4}{|l|}{ Assess mobility and self-care capabilities on admission to the ward with } \\
\hline a) FIM scale & $1.818(0.982)$ & $1.727(0.273)$ & 0.655 \\
\hline b) scale in patient electronic health records & $2.909(1.640)$ & $3.091^{\mathrm{a}}(1.446)$ & 0.672 \\
\hline c) both FIM scale and scale in electronic patient health records & $1.750(1.036)$ & $2.000^{\mathrm{a}}(1.195)$ & 0.157 \\
\hline $\begin{array}{l}\text { Assist patient with getting in and out of the bed on the first } \\
\text { shift on the ward }\end{array}$ & $4.077(0.760)$ & $4.231^{\mathrm{a}}(0.726)$ & 0.157 \\
\hline Assist and supervise patient to transfer between bed and chair & $4.462(0.877)$ & $4.615^{\mathrm{a}}(0.650)$ & 0.157 \\
\hline $\begin{array}{l}\text { Assist and supervise patient with exercises according to physical } \\
\text { therapists' recommendations }\end{array}$ & $3.692((1.032)$ & $4.308^{b}(0.947)$ & $0.023^{b}$ \\
\hline Assist patient in $\mathrm{ADL}$ and coach transferral of exercises into $\mathrm{ADL}$ & $4.308(1.109)$ & $4.385^{\mathrm{a}}(0.768)$ & 0.739 \\
\hline Assist patient with hemiplegia to exercise the paralysed arm & $3.462(1.050)$ & $3.615^{\mathrm{a}}(1.193)$ & 0.564 \\
\hline $\begin{array}{l}\text { Assist patient with hemiplegia to make personal goals in } \\
\text { writing if needed }\end{array}$ & $3.846(1.068)$ & $3.769(1.166)$ & 0.705 \\
\hline \multicolumn{4}{|l|}{ Falls } \\
\hline Assess risk of falls with MORSE scale & $2.846(1.519)$ & $3.231^{\mathrm{a}}(1.092)$ & 0.129 \\
\hline \multicolumn{4}{|l|}{ Pain } \\
\hline Prevent shoulder pain by comforting the paralysed arm & $4.846(0.376)$ & $4.923^{\mathrm{a}}(0.277)$ & 0.317 \\
\hline Teach patient how to prevent shoulder pain & $4.000(1.000)$ & $4.308^{\mathrm{a}}(1.109)$ & 0.234 \\
\hline Teach family how to prevent shoulder pain & $3.417(0.669)$ & $3.667^{\mathrm{a}}(0.888)$ & 0.317 \\
\hline Grade patient's pain by pain scale & $3.692(1.109)$ & $3.385(0.961)$ & 0.157 \\
\hline Use non-pharmacological pain interventions & $3.250(1.056)$ & $3.833^{\mathrm{a}}(0.835)$ & 0.107 \\
\hline \multicolumn{4}{|l|}{ Depression } \\
\hline Assess symptoms of depression with a depression scale & $1.231(0.599)$ & $1.846^{\mathrm{b}}(0.801)$ & $0.033^{b}$ \\
\hline Refer patient to a psychologist due to depression & $2.857(1.351)$ & $3.071^{b}(1.207)$ & 0.438 \\
\hline Refer patient to other HCPs e.g., chaplain or social worker & $2.750(1.139)$ & $2.500(0.798)$ & 0.180 \\
\hline Provide emotional support e.g., with active listening & $4.429(0.646)$ & $4.214(0.699)$ & 0.083 \\
\hline $\begin{array}{l}\text { Encourage patient to believe in own ability by identifying } \\
\text { his/her strength and progress in the rehabilitation }\end{array}$ & $4.643(0.497)$ & $4.286(0.611)$ & $0.025^{* b}$ \\
\hline Coach patient to relax e.g., by listening to music & $3.167(1.267)$ & $3.500^{\mathrm{a}}(1.382)$ & 0.305 \\
\hline Take time to talk with patient & $4.143(0.663)$ & $4.429^{b}(0.514)$ & $0.046^{b}$ \\
\hline Take time to talk with family & $4.071(0.730)$ & $4.357^{\mathrm{b}}(0.633)$ & $0.046^{b}$ \\
\hline \multicolumn{4}{|l|}{ Patient teaching } \\
\hline Give patient individualized teaching material upon admission & $2.583(1.240)$ & $2.833^{\mathrm{a}}(1.193)$ & 0.048 \\
\hline $\begin{array}{l}\text { Secure patient teaching about stroke, its consequences and } \\
\text { planned diagnostic tests and treatment }\end{array}$ & $3.071(1.269)$ & $3.429^{\mathrm{a}}(1.089)$ & 0.227 \\
\hline $\begin{array}{l}\text { Secure family teaching about stroke, its consequences and } \\
\text { planned diagnostic tests and treatment }\end{array}$ & $3.077(1.188)$ & $3.615^{\mathrm{a}}(0.650)$ & 0.052 \\
\hline $\begin{array}{l}\text { Teach patient about the importance that the family } \\
\text { participates with patient in rehabilitation }\end{array}$ & $3.692(1.437)$ & $3.846^{\mathrm{a}}(1.068)$ & 0.564 \\
\hline $\begin{array}{l}\text { Teach family about the importance of their } \\
\text { participation with patient in rehabilitation }\end{array}$ & $3.667(1.371)$ & $3.917^{*}(1.165)$ & 0.257 \\
\hline \multicolumn{4}{|l|}{ Discharge planning } \\
\hline $\begin{array}{l}\text { Document discharge planning in patient } \\
\text { electronic health records }\end{array}$ & $2.833(1.267)$ & $3.917^{\mathrm{b}}(1.084)$ & $0.012^{b}$ \\
\hline $\begin{array}{l}\text { Assess patient's need for social support } \\
\text { after discharge }\end{array}$ & $4.214(0.893)$ & $4.143(0.864)$ & 0.739 \\
\hline
\end{tabular}


Table 4 Difference in nurses' application of 30 quality indicators before and after implementation of the Stroke Nursing Guideline $(N=14)$ (Continued)

\begin{tabular}{lll}
\hline & Pre-test group M (SD) & Post-test group M (SD) \\
\hline $\begin{array}{l}\text { Assess mobility and self-care capabilities in discharge } \\
\text { planning with }\end{array}$ & & \\
a) FIM scale & $1.727(1.272)$ & $2.000^{\mathrm{a}}(1.095)$ \\
$\begin{array}{l}\text { b) scale in patient electronic health records } \\
\text { c) both FIM scale and scale in electronic patient }\end{array}$ & $2.500(1.650)$ & $2.700^{\mathrm{a}}(1.494)$ \\
health records & $2.125(1.356)$ & $1.750(1.165)$ \\
Conduct discharge planning interview, provide & $3.000(1.291)$ & $2.923(1.256)$
\end{tabular}

${ }^{a}=$ differences,${ }^{b}=$ significant differences

care of hospitalized patients with stroke. Both the documentation and quality indicators showed that the nursing staff applied more mobility and ADL interventions, which included screening functional status and providing patients with exercise and training, and interventions focusing on education of patients and family all of which was supported by the qualitative findings. Also, satisfactory attention was paid to observing and assessing patients for the symptoms of depression which was also supported by the qualitative findings.

The feasibility and usefulness of the SNG, both the quantitative and qualitative findings showed that the nursing staff found the SNG useful. The findings of the focus group interviews also showed that the SNG recommendations were practical and easy to use and that it improved nursing care. The guideline layout was also illustrative and instructive for patients and family members.

Contrary to what was anticipated the facilitating factors on the BFAI instrument after implementation were lower for the subscales of "Innovation" and "Context" and no change was found for the "Professional" and "Patient" subscales. The qualitative findings, however, showed relatively positive experiences. The nursing staff judged the implementation to be successful, which was rated with the mean score of 7.5. They reported that they had taken an active part in the implementation. The implementation had brought a totally new view on mobilization in daily care and they found that consistent and coherent leadership had been provided during implementation. Through the SNG, essential components of rehabilitation had been defined and integrated into daily nursing care. Less visible aspects of nursing now received more attention and recognition. Explanation for this mismatch may be found in the questions of the BAFI which generally refer to the context and professional issues on the ward. At the time of the implementation of the guideline, severe organizational and budgetary restrictions were taking place.

The study showed improved documentation by the nursing staff after implementation of the SNG in 23 items focusing on screening and application of interventions. Significant improvements were found in three items focusing on Mobility and ADL. Likewise, parallel findings were found in that the nurses used the SNG more on the items Mobility and $A D L$ indicators and with significant improvement in Assisting and supervising patients with exercises according to physical therapists recommendations, which was in line with the scores on the QIT. This was as well supported by the qualitative findings of the focus group interviews. The SNG provided consistency in care, particularly as the patients did exercises in the same way and there was more consistency in intensity and frequency of exercises. This indicates that the nursing staff generally paid more attention to mobility and ADL, conducting mobility assessments and actually mobilizing patients and providing them with exercises. This finding is in line with the findings of our earlier study investigating the feasibility of the CNRS-Guideline implemented in various stroke settings in the Netherlands [19]. It is however important to note that our study measured the documentation by the nursing staff and not the patient outcomes. However, various studies have shown that health care professionals pay limited attention to mobilizing patients with stroke. A recent intervention study comparing the amount of time spent in moderate-to high physical activity of stroke survivors on rehabilitation ward and acute stroke wards in Sweden showed that the amount of time spent in moderate-to high physical activity ranged between $24 \%$ on a rehabilitation ward and $23 \%$ on acute ward with no difference between the two groups. Compared to those in the acute setting, participants in the rehabilitation setting spent less time lying in bed, more time sitting supported out of bed, less time in their bedroom, and more time with a therapist (all adjusted $P<.001$ ) [56]. An observational behavioral mapping study, showed that stroke patients different medical wards were found inactive and alone for 19 to $15 \%$ of the time during the day and spent $46 \%$ of the time in therapeutic activities and $31 \%$ of the time in nontherapeutic activities. The family was present with patients $50 \%$ of the time during the day. The family presence with 
Table 5 Nurses view of the usefulness of the Stroke Nursing Guideline and Implementation process ( $N=16)$

\begin{tabular}{|c|c|c|}
\hline Mean & Themes & Descriptions \\
\hline \multicolumn{3}{|c|}{ Usefulness of the Stroke Nursing Guideline } \\
\hline $\begin{array}{l}\text { Mean }=7.7 \quad 1 . \\
\text { Range } \\
=5.5-9.0\end{array}$ & $\begin{array}{l}\text { Improved quality of } \\
\text { care }\end{array}$ & $\begin{array}{l}\text { This theme described how the SNG } \\
\text { generally improved nursing care generally. }\end{array}$ \\
\hline
\end{tabular}
Quotes

Implementation process

\begin{tabular}{|c|c|}
\hline $\begin{array}{l}\text { Mean }=7.5 \\
\text { Range } \\
6.0-8.5\end{array}$ & $\begin{array}{l}\text { 1. Nursing } \\
\text { rehabilitation } \\
\text { defined and } \\
\text { integrated }\end{array}$ \\
\hline
\end{tabular}

2. Content known to staff

3. Convenient and concise

4. More use of instruments

5. More consistency

6. Illustrative and instructive
2. Physical exercise Individualized
The content of the SNG was generally known to staff and already used to an extent in daily care.

The SNG was convenient and teh text was concise, effortless to read, handy and practical, particularly for new staff and students.

Screening tools make staff focus more systematically on respective components e.g., depression, anxiety, risk of fall, and nutritional status, to be accurate in communicating about patients'symptoms, as well as to evaluate patients'progress.

The SNG makes staff do things the same way, which is a quality issue, and with consistent intensity and frequency e.g., in doing physcial exercises with more rigorousness in the evenings and weekends.

Concenring the layout of the SNG, the photos and diagrams are illustrative and instructive a) for staff who uses better ergonomics and b) for patients who are mobilized in a convenient and consistent way and c) for family members who can trust that patients receive the right care.
"The SNG has improved the way we work, especially when assisting patients with moving and positioning".

"The SNG has both improved the care, we think more about how we approach patients and how we help them with movement and ADL". "We do not only think about physical care but also psychological care, like depression".

"We ask patients more about how they feel, - their psychological well being".

"We make much more use of scales now".

"We think more about the emotional par now and not only about the phhysical".

"The SNG had not so much new things in it, but very good to have everything set up like this".

"Some things were known to us already, but others are new, like more emphasis on scales and of course depression".

"The recommendations are convenient and really very practical and fit very well with how we work on the wards".

"The guideline is very easy to use. They (the recommendations) are not so extensive, they are short and easy to use".

"The guideline is very easy to use".

"We have had much new nursing staff and then it is very good to have the guideline".

"We use instruments more, especially the PHQ-9".

"We are using the scales much more now with the guideline".

"Now we use scales for most things like walking ability, falls, depression".

"The scales are very easy and practical to use".

"After following SNG and the training, we are all working in the same way, - there is much more consistency in how we move patients".

"It is good that we are all working in the same way. For example when we are taking patients out of bed. Before the guideline we did this very differently".

"We use the photos to show patients and family when patients go home for the weekend".

"Good positions for in bed or when sitting, but also concerning the pain".

"We can use the SNG much more with family".

Through the SNG, essential components of nursing rehabilitation have been defined and integrated into daily nursing care, e.g., going to the toilet is an opportunity to exercise stand up and sit down, rather than only being the fullfilment of a basic human need.

Physcial exercise guidelines have made individualized instructions from physical therapists less needed.

3. Enhanced patient Enhanced patient and family teaching, and family with particularly good teaching material teaching much more clear now. Very clear guideline".

"All these elements of nursing, like moving and ADL, screening for falls, mobility or depression, which were somehow hidden, are more clear now".

"Integrating exercise into daily activities is so good for the patients".

"We now say: Do you need to go to the toilet? Yes, great! That is exercise (laughs)".

"We now do much more of general training, - activating patients".

"The mobililty ADL part of the guideline is very good, gives good instruction on how to mobilize patients. Also positioning, especially the arm".

"Very good to have the photo's on mobility and positioning, we are becoming much better in helping and instructing on how to move and do excercies".

"It is much better to teach patients and family about mobility and integrating exercises into daily activities when having this written down and digital".
"The SNG is very compact. There is not so much new, - but it is 
Table 5 Nurses view of the usefulness of the Stroke Nursing Guideline and Implementation process ( $\mathrm{N}=16)(\mathrm{Continued})$

\begin{tabular}{|c|c|c|c|c|}
\hline Mean & & Themes & Descriptions & Quotes \\
\hline & & & $\begin{array}{l}\text { (booklet), bringing forth a request for } \\
\text { structured family interviews. }\end{array}$ & $\begin{array}{l}\text { "I like to have this in a printed map, which you can take with you } \\
\text { and show to patients and family". }\end{array}$ \\
\hline & 4. & $\begin{array}{l}\text { Coherent and } \\
\text { consistent } \\
\text { leadership }\end{array}$ & $\begin{array}{l}\text { Leadership of the charing group during } \\
\text { implementation of the SNG was } \\
\text { coherent and consistent. }\end{array}$ & $\begin{array}{l}\text { "The implementation went very well". } \\
\text { "The implementation was well led by the chairing group, - they } \\
\text { did a very good follow up on things". } \\
\text { "They (the charing group) really were in charge of things". }\end{array}$ \\
\hline & 5. & $\begin{array}{l}\text { Improved staff } \\
\text { education }\end{array}$ & $\begin{array}{l}\text { The SNG resulted in good/improved } \\
\text { staff education, which needs to be } \\
\text { repeated consistently throughout } \\
\text { the care continuoum. }\end{array}$ & $\begin{array}{l}\text { "The educational and training sessions for staff were very good, - } \\
\text { but it needs to be repeated regulary". } \\
\text { "It is much better to have an active training like this, - you need } \\
\text { to do the things and not only read about them". } \\
\text { "We need to have the training sessions repeated regularly to } \\
\text { refresh things, - you tend to forget". }\end{array}$ \\
\hline & 6. & $\begin{array}{l}\text { Less visible nursing } \\
\text { care received } \\
\text { attention }\end{array}$ & $\begin{array}{l}\text { Through the SNG, previous less visible } \\
\text { aspects of nursing care have received } \\
\text { attention and recognition among all } \\
\text { staff, particularly its contribution to } \\
\text { the success of patient rehabilitation. }\end{array}$ & $\begin{array}{l}\text { "Posters with photo's on positioning and mobilizing of patients } \\
\text { have been put on the walls for patients and famly as well for } \\
\text { staff. Nursing and what we do in rehabilitation is now more } \\
\text { visible for all staff". } \\
\text { "The guideline has made elements of nursing care much more } \\
\text { visible to other staff as wel". } \\
\text { "What we nurses are doing in rehabilitation, like mobilizing and } \\
\text { stimulating patients to exercise is now much more visible to the } \\
\text { other staff". }\end{array}$ \\
\hline
\end{tabular}

the patient and the patient's moderate dependence in daily activities were positively associated with their activity levels. The authors concluded that the presence of family members with the patients during hospital stay may be a significant resource for encouraging patients to be more active [57]. Two smaller studies showed that patients in Dutch nursing homes were inactive and alone for up to $49 \%$ and $60 \%$ of the day $[58,59]$. Therapeutic time use was significantly related to improved functional status; patients with higher functional status spent more time on therapeutic activities [58]. It is highly important that nursing staff activate patients and provide them with opportunities to do exercises in between physical therapy and occupational therapy training sessions and the findings of this study suggest that the SNG is exactly facilitative of that.

Depressive symptoms were only measured postintervention as the nurses did not conduct screening of depression prior to the implementation of the SNG. After implementation of the SNG, the application of the SNG recommendations was quite satisfactory as three out of four items on the QIT were used. This was supported by the qualitative findings of the focus group interviews which showed that the nurses paid more attention to depression and they used the PHQ-9 for screening. In our earlier study, investigating the feasibility of the CNRS-Guideline implemented in various Dutch stroke settings, we found that the nurses acknowledge the importance of assessing and acknowledging the symptoms of depression, but they rarely used recommended instruments for screening depression or evidence based interventions [19]. Depression after stroke is frequent and strongly impacts patients' recovery as patients have worse functional outcome, lower quality of life and are at more risk of dying [27, 28, 60, 61]. There is however growing evidence for the beneficial effects of physical activity [62], self-efficacy [18, 63] and social support [64] all of which can be used by nurses in the daily care of patients with stroke.

This study shows that after the implementation of the SNG the nurses reported enhanced patient and family teaching and that they provided good teaching material that focused on patients and family. This extends

Table 6 Difference on the Barriers and Facilitators Assessment Instrument before and after. implementing the Stroke Nursing Guideline $(N=20)$

\begin{tabular}{lllll}
\hline & Item & Pre-test group & Post-test group & $p$-value \\
\hline & $(N=27)$ & M (SD) & M (SD) & \\
Innovation & 6 & $4.017(0.492)$ & $3.755(0.509)$ & $0.0199^{a}$ \\
Professional & 10 & $3.874(0.445)$ & $3.821(0.675)$ & 0.074 \\
Patient & 6 & $3.392(0.630)$ & $3.415(0.563)$ & 0.055 \\
Context & 5 & $2.632(0.547)$ & $2.474(0.542)$ & $0.001^{a}$ \\
\hline
\end{tabular}

${ }^{\mathrm{a} A} p$-value cursive indicates significant difference between groups 
previous research which has pointed to the importance of patient and family education albeit with a lack thereof [40]. A meta-analysis including 21 trials (2289 patients and 1290 caregivers) and assessing the effectiveness of education provided to patients with stroke and their caregivers, provided evidence that education improves patient and caregiver knowledge of stroke, aspects of patient satisfaction, and reduces patient depression scores. The authors recommend that, although the best way to provide education is still unclear, there is some evidence that strategies that actively involve patients and caregivers in education and includes planned follow-up for clarification and reinforcement have a greater effect on patient mood [65].

Although the study showed improved documentation and use of the SNG on items focusing on mobility and activities of daily living, depressive symptoms, patient teaching and discharge planning, the results of the study show that the implementation and use of the SNG still can be improved on items focusing on pain or falls. The question remains as to why the other elements of the SNG were not as well applied. The nursing staff generally judged the guideline to be practical and easy to use. Earlier studies, however, have reported similar results. Metzelthin and colleagues [66] investigated the implementation of a nurse-led interdisciplinary primary care approach using a process evaluation and concluded that some parts of the program were insufficiently executed [66]. Similar findings were reported in a mixed method study investigating care delivery of a nurse-led intervention, where some time-consuming interventions were less often applied than other interventions [67]. A feasibility study of a fall-prevention program, where interventions that required more knowledge, communication and extra activities were implemented the least. The absence of materials and knowledge about falls prevention were important determinants of the non-implementation of certain interventions [68]. However, given the complexity of guidelines like the SNG, implementation is challenging and needs continuous education of nursing staff and other professionals. It is highly important to continuously monitor and evaluate the implementation and use of the SNG and to verify the extent to which the SNG recommendations are delivered as intended. Further research is warranted into the development and testing as well as implementation and translation of complex interventions like the SNG into the daily care of patients with stroke.

\section{Strengths and limitations}

To appreciate the findings of this study, some limitations need to be considered. The fact that the study took place on only two wards within the same hospital and the fact that the sample of nurses participating was a small convenience sample, which was due to intense workload of nurses, unprecedented staffing shortages, including organizational changes occurring at the same time, and is in line with earlier studies $[19,69,70]$. Therefore, caution is indicated in generalizing the results of this study to other nurses in different organizational settings. However, the demographic data from both nurses and patients participating in our study do reflect the Icelandic population. Although we conducted thorough translation procedure of the instruments used no psychometric testing was conducted. The researchers participated in the development of the guideline and the implementation process, which could have limited objectivity. However, because of the quality assurances taken, the quality of the data can be ensured. The implementation strategies used was based on the literature, with active and multifaceted aspects, which benefited the study $[44,45]$. The mixed method design provided rich data. The findings of the qualitative part were illustrative of the findings of the quantitative findings of the study to which they provided more depth.

Some may, however, consider the design of the study to be limited by the fact that we measured difference in the nurses documentation of SNG key interventions before and after implementation and not difference in patient outcomes. It is important to note that this study was not an outcome study, but a feasibility study investigating the usability of the SNG and documentation of interventions is an important parameter in measuring usability. Further, robust outcome studies are warranted to investigate the effects of the SNG on various patient outcomes including larger samples with a longer followup period.

\section{Conclusions}

The findings of this study indicate that implementation of the SNG improved patient care as illustrated in the patient electronic documentation system, nurses answers on the Quality Indicators Tool and focus group interview with nursing staff. Most improvements were found on assessing mobility and ADL and patients were activated more and they as well participated more in exercise and training. The nursing staff gave more education to patients and families and they paid more attention to the symptoms of depression and screened patients for depression. Using the SNG, the essential components of rehabilitation were defined and integrated into daily nursing care. The nursing staff found the SNG feasible and that it was practical and easy to use and it improved nursing care. The guideline layout was illustrative and instructive for patients and family members. The nursing staff judged the implementation of the SNG to be successful and they generally took an active part in the implementation. The SNG needs to be further developed and robust research needs to be conducted to investigate 
the effects of the SNG on the outcomes of patients with stroke in various settings where patients with stroke reside. Thereby we may be able to improve the clinical outcomes of patients with stroke.

\section{Additional files}

$$
\begin{aligned}
& \text { Additional file 1: STROBE and COREQ statements. (DOC } 131 \mathrm{~kb} \text { ) } \\
& \text { Additional file 2: Interview guide. (DOCX } 16 \mathrm{~kb} \text { ) }
\end{aligned}
$$

\section{Abbreviations}

ADL: Activities of Daily Living; BFAl: Barriers and Facilitators Assessment Instrument; CNRSG: Clinical Nursing Rehabilitation Stroke-guideline; CPG: Clinical Practice Guidelines; FIM: Functional Independence Measure; HJ: Helga Jónsdóttir; IB: Ingibjörg Bjartmarz; MFS-I: Morse Fall Scale-Icelandic; MSF: Morse Fall Scale; PHQ-9: Patient Health Questionnaire-9; QIT: Quality Indicator Tool;; SNG: Stroke Nursing Guideline; TBH: Thóra B. Hafsteinsdóttir

\section{Acknowledgements}

The authors thank all the participants for taking part in the study. Especially we would like to thank the nurses and nursing auxiliaries and warm thanks to dr. Ingibjörg Hjaltadóttir, Guðrún Sigurjónsdóttir and Ester Sighvatsdóttir for their help with the focus group discussion in this study.

\section{Funding}

This study was funded by the Icelandic Nursing Association, Scientific Fund B (2012) and Scientific Fund of Landspítali University Hospital, Reykjavík Iceland (2012). The funding bodies had no role in the design of the study, data collection, analysis, interpretation of data or in the writing of this manuscript.

\section{Availability of data and materials}

There are no additional unpublished data for this paper. Data is stored safely and appropriately according to the guidelines for storing research materials at Faculty of Nursing, University of Iceland and Landspítali University Hospital. All the data used in this study including the transcripts of the qualitative part of the study were written in Icelandic, which makes them difficult to share. For the request of raw data, please contact the last author.

\section{Authors' contributions}

$\mathrm{HJ}$, TBH designed the study, IB collected the data, IB and HJ conducted the data analysis. All authors discussed the findings and contributed equally to the writing of the manuscript. All authors secured funding for this research project. All authors read and approved the final manuscript.

\section{Ethics approval and consent to participate}

Ethical approval was granted by the Hospital Ethics Committee (1909201223-2012, 0411201323-2012, 1,701,201,423-2012,1,603,201,5232012, 1,007,201,523-2012, 23/2012), the Ethics Committee of the CEO of Medicine $(3,005,201,516,16 \mathrm{LSH}-14,1,203,201,516)$, Human Resource Council of the hospital (2505201216) and the Data protection Authorities $(2,012,050,710$, $2,014,010,073$, S6717-2014). All the nurses and nursing auxiliaries consented to participation in this study and the use of direct quotes in this paper by signing an informed consent form.

\section{Consent for publication}

Not applicable.

\section{Competing interests}

The authors declare that they have no competing interests.

\section{Publisher's Note}

Springer Nature remains neutral with regard to jurisdictional claims in published maps and institutional affiliations.

\section{Author details}

'Clinical Nurse Specialist, Department of Rehabilitation, Landspítali University Hospital, Reykjavík, Iceland. 'Faculty of Nursing, University of Iceland, Reykjavík, Iceland. ${ }^{3}$ Nursing Care for Chronically III Adults, Landspítali University Hospital, Reykjavík, Iceland. ${ }^{4} J u l i u s$ Center for Health Sciences and Primary Care, Nursing Science Department, University Medical Center Utrecht, Utrecht, The Netherlands.

Received: 20 March 2017 Accepted: 10 November 2017

Published online: 01 December 2017

\section{References}

1. Feigin VL, Mensah GA, Norrving B, Murray CJ, Roth GA. GBD 2013 Stroke Panel Experts Group. Atlas of the Global Burden of Stroke (1990-2013): The GBD 2013 Study. Neuroepidemiology. 2013;45(3):230-6.

2. Miller EL, Murray L, Richards L, Zorowitz RD, Bakas T, Clark P, et al. Comprehensive Overview of Nursing and Interdisciplinary Rehabilitation Care of the Stroke Patient A Scientific Statement from the American Heart Association. Stroke. 2010;41(10):2402-48.

3. Poslawsky IE, Schuurmans MJ, Lindeman E, Hafsteinsdóttir TB. A systematic review of nursing rehabilitation of stroke patients with aphasia. J Clin Nurs. 2010;19:17-32.

4. Wright L, Hill KM, Bernhardt J, Lindley R, Ada L, Bajorek BV, et al. National Stroke Foundation Stroke Guidelines Expert Working Group. Stroke management: updated recommendations for treatment along the care continuum. Intern Med J. 2012:42(5):562-9.

5. Kirkevold M. The Role of Nursing in the Rehabilitation of Stroke Survivors: An Extended Theoretical Account. Adv Nurs Sci. 2010;33(1):E27-40.

6. Langhorne P, Bernhardt J, Kwakkel G. Stroke rehabilitation. Lancet. 2011; 14(377):1693-17.

7. Lee JH, van der Snels IA, Beckerman H, Lankhorst GJ, Wagenaar RC, Bouter LM. Exercise therapy for arm function in stroke patients: a systematic review of randomized controlled trials. Clin Rehabil. 2001;15(1):20-31.

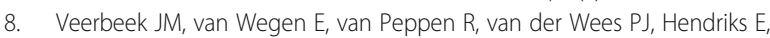
Rietberg M, et al. 2014. What is the evidence for physical therapy poststroke? A systematic review and meta-analysis. PLoS One. 2014;4:9(2): e87987.

9. Rensink M, Schuurmans M, Lindeman E, Hafsteinsdóttir T. Task oriented training in rehabilitation after stroke: systematic review. J Adv Nurs. 2009;65: 737-54.

10. Melnyk BM, Gallagher-Ford L, Long LE, Fineout-Overholt E. The establishment of evidence-based practice competencies for practicing registered nurses and advanced practice nurses in real-world clinical settings: proficiencies to improve healthcare quality, reliability, patient outcomes, and costs. Worldviews Evid Based Nurs. 2014;11(1):5-15.

11. van Peppen RP, Hendriks HJ, van Meeteren NL, Helders PJ, Kwakkel G. The development of a clinical practice stroke guideline for physiotherapists in The Netherlands: a systematic review of available evidence. Disabil Rehabil. 2007;29(10):767-83.

12. van Achterberg T, Schoonhoven L, Grol R. Nursing implementation science: how evidence-based nursing requires evidence-based implementation. J Nurs Scholarsh. 2008:40(4):302-10.

13. Hafsteinsdóttir TB, Schuurmans MM. Clinical Nursing Rehabilitation StrokeGuideline [Verpleegkundige Revalidatierichtlijn Beroerte]. Elsevier Gezondheidszorg: Maarsen; 2009.

14. de Man-van Ginkel JM, Gooskens F, Schuurmans MJ, Lindeman E, Hafsteinsdottir TB. Rehabilitation Guideline Stroke Working Group. A systematic review of therapeutic interventions for post-stroke depression and the role of nurses. J Clin Nurs. 2010;19:3274-90.

15. van Dijk MJ, de Man-van Ginkel JM, Hafsteinsdóttir TB, Schuurmans MJ. Identifying depression post-stroke in patients with aphasia: a systematic review of the reliability, validity and feasibility of available instruments. Clin Rehabil. 2016;30(8):795-810.

16. Rensink M, Schuurmans M, Lindeman E, Hafsteinsdóttir TB. Falls: incidence and risk factors after stroke. A systematic literature review Vallen: Incidentie en risicofactoren bij patiënten met een beroerte. Een systematisch literatuuronderzoek]. Tijdschr Gerontol Geriatr. 2009a;40(4):156-67.

17. Klinke ME, Hafsteinsdóttir TB, Hjaltason H, Jónsdóttir H. Ward-based interventions for patients with hemispatial neglect in stroke rehabilitation: a systematic literature review. Int J Nurs Stud. 2015;52(8):1375-403. 
18. Korpershoek C, van der Bijl J, Hafsteinsdóttir TB. Self-efficacy and its influence on recovery of patients with stroke: a systematic review. J Adv Nurs. 2011;67:1876-94.

19. Hafsteinsdóttir TB, Varekamp R, Rensink M, van Linge R, Lindeman E, Schuurmans M. Rehabilitation Guideline Stroke Working Group. Feasibility of a nursing rehabilitation guideline for patients with stroke: evaluating the use by nurses. Disabil Rehabil. 2013;35(11):939-49.

20. de Man-van Ginkel JM, Hafsteinsdóttir T, Lindeman E, Burger H, Grobbee D, Schuurmans M. An efficient way to detect post-stroke depression by subsequent administration of a 9-item and a 2-item Patient Health Questionnaire. Stroke. 2012b;43(3):854-6.

21. de Man-van Ginkel JM, Hafsteinsdóttir TB, Lindeman E, Geerlings MI, Grobbee DE, Schuurmans MJ. Clinical Manifestation of Depression after Stroke: Is It Different from Depression in Other Patient Populations? PLoS One. 2015 Dec 4;10(12):e0144450.

22. van Dijk MJ, de Man-van Ginkel JM, Hafsteinsdóttir TB, Schuurmans MJ. Psychometric evaluation of the Signs of Depression Scale with a revised scoring mechanism in stroke patients with communicative impairment. Clin Rehabil. 2017 May 1:269215517708328. doi: https://doi.org/10.1177/ 0269215517708328. [Epub ahead of print]

23. van Dijk MJ, de Man-van Ginkel JM, Hafsteinsdóttir TB, Schuurmans MJ. Psychometric Properties of the Dutch Version of the Signs of Depression Scale. Clin Nurs Res. 2016 Jul 5. pii: 1054773816657798. [Epub ahead of print]

24. Bjartmarz I, Hafsteinsdóttir TB, Jónsdóttir H. Stroke Nursing Guideline: Rehabilitation nursing care of patients with stroke [Klínískar leiðbeiningar: Hjúkrun sjúklinga í endurhæfingu eftir heilablóðfall]. Reykjavík Iceland: Landspítali University Hospital; 2013.

25. Li Z, Alexander SA. 2015. Current evidence in the management of poststroke hemiplegic shoulder pain: a review. J Neurosci Nurs. 2015; 47(1):10-9.

26. Zhao H, Nie W, Sun Y, Li S, Yang S, Meng F, et al. Warm Needling Therapy and Acupuncture at Meridian-Sinew Sites Based on the Meridian-Sinew Theory: Hemiplegic Shoulder Pain. Evid. Based Complement. Alternat Med. 2015; https://doi.org/10.1155/2015/694973. Epub 2015 Oct 1.

27. Hackett M L, Pickles M. Part I: Frequency of Depression After Stroke: An Updated Systematic Review and Meta-analysis of Observational Studies. Int J Stroke. 2014;9(8):1017-1025.

28. Robinson RG, Jorge RE. Post-Stroke Depression: A Review. Am J Psychiatry. 2016;173(3):221-31.

29. Kouwenhoven SE, Kirkevold M, Engedal K, Kim HS. Living a Life in Shades of Grey: Experiencing Depressive Symptoms in the Acute Phase After Stroke. J Adv Nurs. 2012;68(8):1726-37.

30. Bartoli F, Lillia N, Lax A, Crocamo C, Mantero V, Carrà G, et al. Depression after stroke and risk of mortality: a systematic review and meta-analysis. Stroke Res Treat. Stroke Res Treat. 2013;862978 https://doi.org/10.1155/2013/ 862978. Epub 2013 Mar 7

31. Edwards DF, Hahn MG, Baum CM, Perlmutter MS, Sheedy C, Dromerick AW. Screening Patients with Stroke for Rehabilitation Needs: Validation of the Post-Stroke Rehabilitation Guidelines. Neurorehabil Neural Repair. 2006;20(1):42

32. de Man-van Ginkel JM, Gooskens F, Schepers VP, Schuurmans MJ, Lindeman E, Hafsteinsdóttir TB. Screening for post-stroke depression using the patient health questionnaire. Nurs Res. 2012a;61(5):333-41.

33. Breisinger TP, Skidmore ER, Niyonkuru C, Terhorst L, Campbell GB. The Stroke Assessment of Fall Risk (SAFR): predictive validity in inpatient stroke rehabilitation. Clin Rehabil. 2014;28(12):1218-24.

34. Campbell GB, Matthews JT. An integrative review of factors associated with falls during post-stroke rehabilitation. J Nurs Scholarsh. 2010:42(4):395-404

35. Czernuszenko A, Członkowska A. Risk factors for falls in stroke patients during inpatient rehabilitation. Clin Rehabil. 2009;23(2):176-88.

36. Maeda N, Urabe Y, Murakami M, Itotani K, Kato J. Discriminant analysis for predictor of falls in stroke patients by using the Berg Balance Scale. Singapore Med J. 2015;56(5):280-3.

37. Schmid AA, Van Puymbroeck M, Knies K, Spangler-Morris C, Watts K, Damush T, Williams LS. Fear of falling among people who have sustained a stroke: a 6-month longitudinal pilot study. Am J Occup Ther. 2011;65(2):125-32.

38. Suzuki T, Sonoda S, Misawa K, Saitoh E, Shimizu Y, Kotake T. Incidence and consequence of falls in inpatient rehabilitation of stroke patients. Exp Aging Res. 2005;4:457-69.
39. Smith J, Forster A, Young J. Cochrane Group for information provision after stroke. Cochrane review: Information provision for stroke patients and their caregivers. Clin Rehabil. 2009;23(3):195-206.

40. Hafsteinsdóttir TB, Vergunst $M$, Lindeman E, Schuurmans M. Educational needs of patients with a stroke and their caregivers: a systematic review of the literature. Patient Educ Couns. 2011:85:14-25.

41. Moore GF, Audrey S, Barker M, Bond L, Bonell C, Hardeman W, et al. Process evaluation of complex interventions: Medical Research Council guidance. BMJ. 2015;19;350:h1258. doi: 10.1136/bmj.h1258.

42. Richards DA, Rahm-Hallberg IR. Complex Interventions in Health. London and New York: Routledge Taylor and Francis Group; 2015.

43. Bowen DJ, Kreuter M, Spring B, Cofta-Woerpel L, Linnan L, Weiner D. How we design feasibility studies. Am J Prev Med. 2009;36(5):452-7.

44. Creswell JW. Research Design: Qualitative, Quantitative \& Mixed Methods Approaches. Fourth edition. Sage Publications, London; 2014.

45. Polit DF, Beck CT. Nursing Research, Generating and Assessing Evidence for Nursing Practice. Philadelphia: Wolters Kluwer Health; 2012

46. Harmsen $M$, Peters $M$, Wensing $M$. Barriers and facilitators assessment instrument Introduction, instructions and instrument. IQ healthcare Scientific Institute for Quality of Healthcare. Radboud University Medical Center Nijmegen; 2005 http://www.iqhealthcare.nl/media/80004/barriers_ and_facilitators_questionnaire.pdf. Accessed 15 January 2012. .

47. Prior M, Guerin M, Grimmer-Somers K. The effectiveness of clinical quideline implementation strategies: a synthesis of systematic review findings. J Eval Clin Pract. 2008;14(5):888-97.

48. Grol R, Wensing M. Implementation: Effective improvement of patient care [Implementatie Effectieve verbetering van de patientenzorg] Elsevier Gezondheidszorg. Amsterdam; 2010.

49. Morse JM. Predicting Patient Falls. CA: Sage Publications; 1997.

50. Schwendimann R, Milisen K, Bühler $H$, De Geest S. Fall prevention in a Swiss acute care hospital setting Reducing multiple falls. J Gerontol Nurs. 2006:32:13-22.

51. Forster A, Brown L, Smith J, House A, Knapp P, Wright JJ, et al. Information Provision for Stroke Patients and their Caregivers. Cochrane Database Syst Rev. 2012;14, 11:CD001919. doi: https://doi.org/10.1002/ 14651858.CD001919 pub3.

52. Functional Independence measure (FIM): Uniform Data System for Medical Rehabilitation. The FIM System ${ }^{\oplus}$ Clinical Guide, Version 5.2. Buffalo: UDSMR; 2009. http://ahsri.uow.edu.au/aroc/whatisfim/index.html Accessed January 2012.

53. Kroenke K, Spitzer RL, Williams JB. The PHQ-9: validity of a brief depression severity measure. J Gen Intern Med. 2001;16(9):606-13.

54. Kroenke K, Spitzer RL, Williams JB. The Patient Health Questionnaire-2: validity of a two-item depression screener. Med Care. 2003;41(11):1284-92

55. World Medical Association (WMA) Declaration of Helsinki: 2013. Ethical Principles for Medical Research Involving Human Subjects; 2013. http:// www.wma.net/en/30publications/10policies/b3/. Accessed 26.01.2015.

56. Åstrand A, Saxin C, Sjöholm A, Skarin M, Linden T, Stoker A, et al. Poststroke Physical Activity Levels No Higher in Rehabilitation than in the Acute Hospital. J Stroke Cerebrovasc Dis. 2015;25(4):938-45.

57. Prakash V, Shah MA, Hariohm K. Family's presence associated with increased physical activity in patients with acute stroke: an observational study. Braz J Phys Ther. 2016;20(4):306-11.

58. Vermeulen CJ, Buijck Bl, van der Stegen JC, van Eijk MS, Koopmans RT, Hafsteinsdóttir TB. Time use of stroke patients with stroke admitted for rehabilitation in Skilled Nursing Facilities. Rehabil Nurs. 2013;38(6):297-305.

59. Huijben-Schoenmakers M, Gamel C, Hafsteinsdóttir T. Filling up the hours: how do stroke patients on a rehabilitation nursing home spend their day. Clin Rehabil. 2009;23:1145-50.

60. Ayerbe L, Ayis S, Wolfe CD, Rudd AG. Natural History, Predictors and Outcomes of Depression After Stroke: Systematic Review and Meta-Analysis. Br J Psych. 2013:202(1):14-21.

61. Ayerbe L, Ayis S, Crichton S, Wolfe CD, Rudd AG. The Long-Term Outcomes of Depression Up to 10 Years After Stroke; the South London Stroke Register. J Neurol Neurosurg Psychiatry. 2014;85(5):514-21.

62. Billinger SA, Arena R, Bernhardt J, Eng JJ, Franklin BA, Johnson CM, et al. Physical Activity and Exercise Recommendations for Stroke Survivors: A Statement for Healthcare Professionals from the American Heart Association/American Stroke Association. Stroke. 2014;45(8):2532-53.

63. Jones F, Riazi A. Self-Efficacy and Self-Management After Stroke: A Systematic Review. Disabil Rehabil. 2011;33(10):797-810. 
64. King RB, Shade-Zeldow Y, Carlson CE, Feldman JL, Philip M. Adaptation to Stroke: A Longitudinal Study of Depressive Symptoms, Physical Health, and Coping Process. Top Stroke Rehabil. 2015;9(1):46-66.

65. Lim JY, Jung SH, Kim WS, Paik NJ. Incidence and risk factors of poststroke falls after discharge from inpatient rehabilitation. Am J Phys Med Rehabil. 2012:4(12):945-53.

66. Metzelthin SF, Daniels R, van Rossum E, Cox K, Habets H, de Witte LP, et al A nurse-led interdisciplinary primary care approach to prevent disability among community-dwelling frail older people: A large-scale process evaluation. Int J Nurs Stud. 2013;50(9):1184-96.

67. Bleijenberg N, Ten Dam VH, Drubbel I, Numans ME, de Wit NJ, Schuurmans MJ. 2016. Treatment Fidelity of an Evidence-Based Nurse-Led Intervention in a Proactive Primary Care Program for Older People. Worldviews Evid Based Nurs. 2016;13(1):75-84.

68. Van Harten-Krouwel D, Schuurmans M, Emmelot-Vonk M, Pel-Littel R. Development and feasibility of falls prevention advice. J Clin Nurs. 2011; 20(19-20):2761-76.

69. McCloskey DJ. Nurses' perceptions of research utilization in a corporate health care system. J Nurs Scholarsh. 2008;40:39-45.

70. Fink R, Thompson CJ, Bonnes D. Overcoming barriers and promoting the use of research in practice. J Nurs Adm. 2005;35:121-9.

\section{Submit your next manuscript to BioMed Central} and we will help you at every step:

- We accept pre-submission inquiries

- Our selector tool helps you to find the most relevant journal

- We provide round the clock customer support

- Convenient online submission

- Thorough peer review

- Inclusion in PubMed and all major indexing services

- Maximum visibility for your research

Submit your manuscript at www.biomedcentral.com/submit 